\title{
PEMANFAATAN INDERAJA DAN SISTEM INFORMASI GEOGRAFIS (SIG) DALAM INVENTARISASI LAHAN KRITIS DI KABUPATEN KOLAKA UTARA
}

\author{
Using Remote Sensing and Geographic Information System (GIS) in Inventarisation Critical Land in the \\ Kolaka Utara Regency \\ Baharuddin
}

\begin{abstract}
At this time the technology required to conduct a study of land mainly related to land change and land condition analysis. To anticiapate this need for technology Remote Sensing and Geographic Information System (GIS) that can quickly and accurately to conduct a study on land resources. Critical land is a condition of land which is the result of an error in the maintenance and land management. Kolaka Utara Regency a new district which has the problem of land mainly biophysical and social condition.In this case the methode used is to land suitability analysis approach based on FAO and determination based on the rules Director General Land Rehabilitation and Social Forestry - DEPHUT, SK.167/V-SET/2004, combined with productivity data field based on their utilization. Based on the analysis with Remote Sensing and GIS in Kolaka Utara Regency result that is dominated by protected forest area of 163.376,51 ha $(53,0 \%)$, followed by limited production forest $65.887,63$ ha $(21 \%)$, cultivation area $60.977,75$ ha. $(19,6 \%)$ and production forest convertion $20.258,94$ ha $(6.5 \%)$. Land use and land cover largest is forest area of $177.850,02$ ha $(57,3 \%)$, cocoa palantation area 91.066 .80 ha $(29,3 \%)$, garden mixed area18.517,76 ha $(6,0 \%)$, shrub area $11.615,40$ ha $(3,7 \%)$, and clove plantation area $4.067,93$ ha $(1,3$ $\%)$. Potential land critical area is $39.040,96$ ha $(12,6 \%)$, land rather critical is $13.513,43$ ha $(4,4 \%)$, critical land is $47.534,21$ ha, $(15,3 \%)$ and land critical immensely is $19.509,42$ ha $(6,3 \%)$, and land while the rest is not critical is $190.902,81$ ha $(61,5 \%)$. Degraded land spread in all areas well outside the region (cultivate area) and within region (forest area).
\end{abstract}

Key words: Inderaja, SIG, critical land

\section{PENDAHULUAN}

\section{Peranan Inderaja dan SIG}

Salah satu aplikasi Inderaja dan GIS dalam lingkup wilayah adalah inventarisasi lahan kritis. Berdasarkan data dari Departemen Kehutanan hingga tahun 2000, luas lahan kritis yang mengalami kerusakan parah di seluruh Indonesia mencapai \pm 8.136 .646 ha untuk kawasan hutan dan $\pm 21.944 .595,70$ ha untuk lahan di luar kawasan hutan. Pada tahun yang sama, kemampuan pemerintah untuk melakukan rehabilitasi hutan dan lahan (RHL) hanya mencapai hanya $2 \%, 12.952$ ha untuk lahan hutan dan 326.973 ha untuk lahan di luar hutan (Nugraha 2008).

Lahan kritis pada umumnya merupakan istilah yang menjadi bahan perbincangan di Departemen Kehutanan di Indonesia. Perbincangan tentang lahan kritis umumnya terkait dengan kawasan hutan baik dalam keperluan untuk rehabilitasi maupun untuk kegiatan alih fungsi pemanfaatan lahan.

Lahan kritis tidak mesti hanya dibicarakan oleh Departemen Kehutanan saja secara sepihak, tetapi merupakan sesuatu yang menjadi pokok perhatian bagi semua pengguna lahan, baik sebagai lahan pertanian, perkebunan, pemukiman, dan industri. Sehingga perlu suatu wadah secara bersama untuk menetapkan suatu wilayah kritis atau potensi kritis pada masa yang akan datang. Untuk memudahkan dalam perencanaan penanganan lahan kritis Departemen Kehutanan melakukan kegiatan dengan menggunakan sistem informasi geografis (SIG) lahan kritis (Departemen Kehutanan, 2004).

Dalam rangka mendapatkan informasi tentang luas lahan kritis di Indonesia maka bukan hanya Departemen Kehutanan diharapkan 
melakukan inventarisasi tetapi semua instansi teknis dapat secara bersama melakukannya. Begitu pula pendekatan yang dilakukan tidak hanya berdasarkan pada penggunaan suatu metode tertentu, tetapi perlu adanya kombinasi dari berbagai metode dengan sumber informasi yang ada sehingga informasi lahan kritis dapat menjadi lebih tepat dan akurat. Dengan ketersedian teknologi remote sensing dan GIS dan pendekatan berbagai metode maka inventarisasi lahan kritis dapat dilakukan.

Paper ini memuat suatu hasil pemanfaatan Inderaja dan SIG adalah mlakukan inventarisasi dan analisis tentang luas dan sebaran lahan kritis di Kabupaten Kolaka Utara.

\section{Lahan Kritis dan Beberapa Aplikasi Inderaja dan SIG.}

Makna lahan akan berbeda-beda berdasarkan latar belakang dan kepentingan masing-masing (Notohadiprawiro, 2004). Selajutnya Notohadiprawiro 2004 dalam sadurannya dari FAO., 1997, dinyatakan bahwa lahan adalah suatu wilayah daratan bumi yang ciri-cirinya mencakup semua tanda pengenal (attributes) atmosfer, tanah, geologi, timbulan (relief), hidrologi dan populasi tumbuhan dan hewan, baik yang bersifat mantap maupun yang bersifat mendaur, serta hasil kegiatan manusia masa lalu dan masa kini, sejauh hal-hal tadi berpengaruh (significant) atas penggunaan lahan pada masa kini dan masa mendatang.

Lahan kritis telah didefenisikan pada Lokakarya Penetapan Kriteria Lahan Kritis tanggal 17 Juni 1997, yang diselenggarakan oleh Direktorat Rehabilitasi dan Konservasi Tanah Departemen Kehutanan RI. Lahan kritis didefinisikan sebagai lahan yang telah mengalami kerusakan, sehingga kehilangan atau berkurang fungsinya sampai pada batas yang ditentukan atau diharapkan. Lahan kritis merupakan lahan atau tanah yang saat ini tidak produktif karena pengelolaan dan penggunaan tanah yang tidak atau kurang memperhatikan syarat-syarat konservasi tanah dan air. Secara umum lahan kritis merupakan salah satu indikator adanya degradasi (penurunan kualitas) lingkungan sebagai dampak dari berbagai jenis pemanfaatan sumber daya lahan yang kurang bijaksana (Prawira, dkk 2005)

Terjadi perubahan secara signifikan penggunaan remote sensing setelah 20 tahun terakhir, (King dan Wardoyo, 1999). Penggunaan penginderaan jauh sudah menjadi persyaratan dalam perencanaan ruang (Baja dan Abd. Madjid Sallatu 2005). Dalam hal ini bagaimana mengkaji karakteristik penutupan lahan, khususnya terjadi proses perubahan yang begitu cepat.

Aplikasi Remote sensing dan GIS merupakan teknologi yang sangat membantu dalam mendeteksi laju perubahan penutupan dan pemanfaatan lahan lahan yang begitu cepat. Dibanding dengan metode teresterial atau pengukuran lapangan maka tidak ada jalan lain selain menggunakan teknologi ini dalam mengantisipasi cepatnya perubahan pemanfaatan lahan, begitupula data dan aplikasinya sangat luas terhadap objek kebumian sehingga persoalan-persoalan yang dihadapi oleh kepentingan yang berbeda dapat digunakan. Salah satu yang sangat penting adalah melihat kondisi sekarang dan kondisi yang akan datang (yaitu berkelanjutan) dalam lahan pertanian dan aplikasinya dalam pengelolaan.(Hellkamp, dkk., 2000 dalam Baja, dkk., 2006).

Remote sensing menyediakan informasi secara spasial dan atributnya yang dalam GIS secara georeferensial dapat dibangun topologinya sehingga secara spasial dan atribut dapat ditampilkan. As management decision are generally made based on the combination of land at attributes, it is important to identify the levels and geographical patterns of biophysical constraints and land degradation potential of the planned area on a spatial and temporal basis (Baja and others 2006). Berdasarkan hal tersebut maka secara umum bahwa tingkat kerusakan lahan dapat dideteksi dengan mudah, cepat, dan biaya lebih murah.

Teknologi GIS digunakan secara luas oleh masyarakat baik saintis, praktis, instansi pemerintah dan masyarakat. Peningkatan secara dramatis didukung oleh ketersediaan perangkat lunak dan perangkat keras (Baja, 2005). Tersedianya berbagai macam citra satelit dengan resolusi yang semakin baik seperti SPOT, Aster, Alos, dan lain-lain sangat mendukung berkembangnya penggunaan remote sensing dan GIS dalam analisis mengenai sumberdaya lahan.

\section{BAHAN DAN METODE}

Dalam metode ini digunakan pendekatan secara bertahap dengan melakukan overlay 
bertahap peta-peta, kesesuain tata-ruang dan penggunaan lahan saat ini. Salah satu analisis dasar yang digunakan dalam penyusunan basis data lahan kritis adalah analisis kesesuaian lahan dan penggunaan lahan aktual. Dalam analisis ini adalah analisis kesesuaian lahan dengan menggunakan metoda $F A O$ dan berdasarkan peta-peta yang tersedia dan data RePPProT.

Untuk penetapan kekritisan lahan dalam suatu wilayah, maka nilai dari setiap faktor dijumlahkan setelah masing-masing dikalikan dengan nilai bobot sesuai dengan besarnya pengaruh relatif terhadap kepekaan wilayah yang bersangkutan. Penentuan kekritisan dengan SIG saat ini, diatur berdasarkan Peraturan Direktur Jendral Rehabilitasi Lahan dan Perhutanan Sosial - DEPHUT, SK.167/V-SET/2004. Dalam aplikasinya, tiap parameter diolah menggunakan metode skoring/WLC untuk mendapatkan nilai kualitatif kekritisan lahan. Persamaan yang digunakan untuk menghitung nilai kekritisan lahan berdasarkan Peraturan Direktur Jendral Rehabilitasi Lahan dan Perhutanan Sosial DEPHUT, SK.167/V-SET/2004 adalah:

$S K O R=(20 \times$ faktor kls lereng $)+(15 \times$ faktor kls penutupan lahan $)+(10 \times$ faktor kls tanah) $+(10 \times$ faktor kls curah hujan $)$

Analisis dasar diarahkan untuk menetapkan tingkat kekritisan lahan. Untuk memperoleh informasi tentang kondisi lahan saat ini (present land use) digunakan citra satelit yang memiliki resolusi spasil yang mendukung untuk mendeteksi tingkat penutupan dan penggunaan lahan. Dalam kajian ini digunakan citra ASTER dengan resolusi spasial $15 \mathrm{~m} \times 15 \mathrm{~m}$. Tingkat kekritisan lahan ditentukan dari jumlah nilai untuk masing-masing kriteria sesuai fungsi lahannya. Tahap selanjutnya adalah menentukan suatu lahan kritis dan potensial kritis. Pendekatan yang dapat dilakukan adalah dengan menggunakan data produktifitas lahan, kesesuaian peruntukannya menurut arahan pemanfaatan lahannya, tingkat degradasi

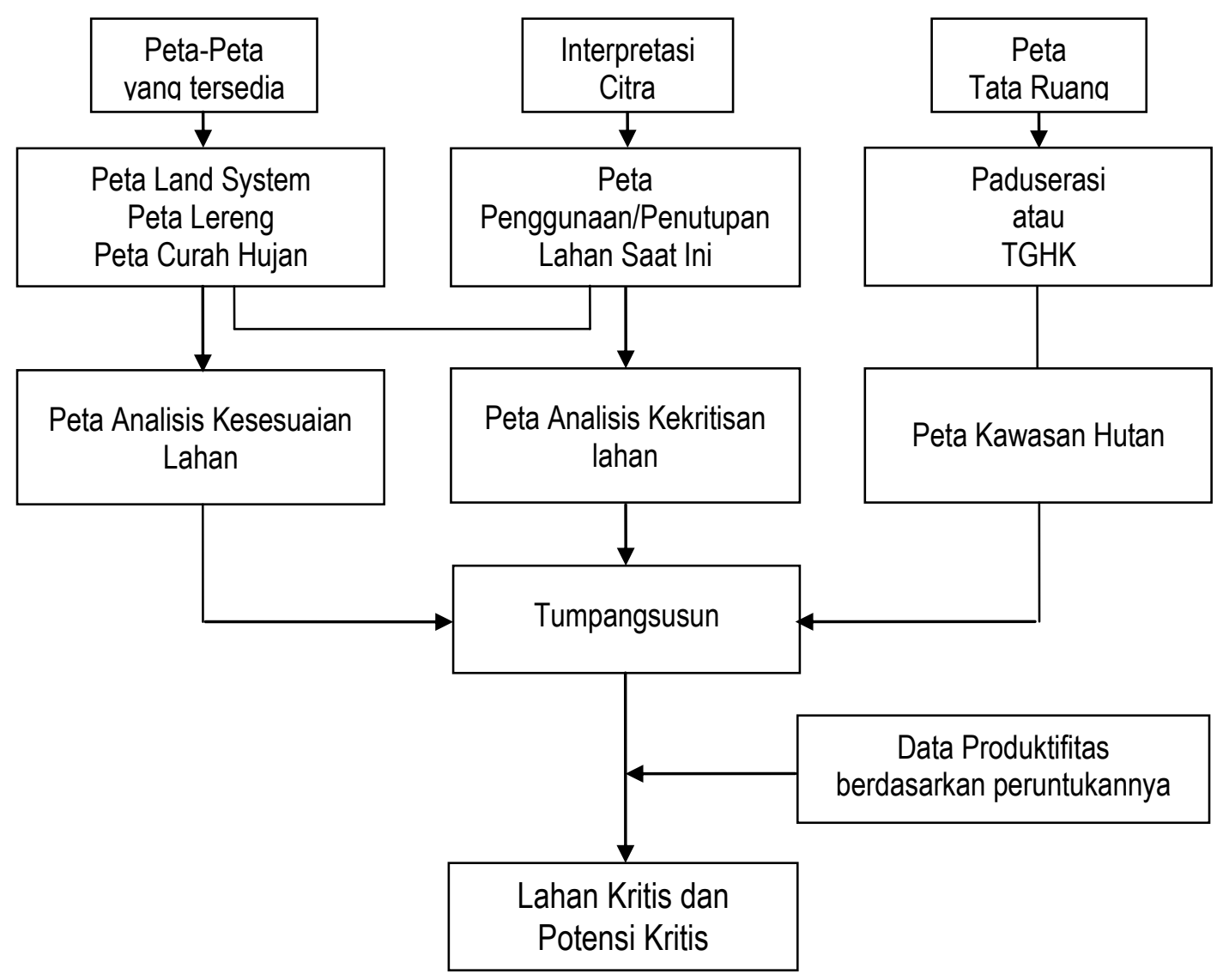

Figure 1. Framework for determination critical land and potential critical 
Table 1. Forest area Kolaka Utara Regency Based on forest status map

\begin{tabular}{|c|c|c|c|c|c|}
\hline \multirow[b]{2}{*}{ District } & \multicolumn{4}{|c|}{ Wide distribution (Ha) } & \multirow[b]{2}{*}{ Total } \\
\hline & $\begin{array}{c}\text { Cultivate } \\
\text { Area }\end{array}$ & $\begin{array}{c}\text { Protection } \\
\text { Forest }\end{array}$ & $\begin{array}{c}\text { Production Foerst } \\
\text { Convertion }\end{array}$ & $\begin{array}{c}\text { Production } \\
\text { Forest Limited }\end{array}$ & \\
\hline Batuputih & $12.067,02$ & $24.241,66$ & $5.304,06$ & $19.305,01$ & $60.917,75$ \\
\hline Katoi & $4.175,02$ & $4.493,07$ & 106,70 & & $8.774,79$ \\
\hline Kodeoha & $7.163,62$ & $18.972,78$ & & 287,21 & $26.423,61$ \\
\hline Lambai & & $9.952,52$ & $3.568,01$ & & $13.520,53$ \\
\hline Lasusua & $3.280,62$ & $15.966,97$ & $4.506,25$ & 705,62 & $24.459,46$ \\
\hline Ngapa & $6.146,11$ & $7.850,21$ & & $1.807,52$ & $15.803,84$ \\
\hline Pakue & $5.098,60$ & $12.073,89$ & & & $17.172,49$ \\
\hline Pakue Tengah & $4.090,38$ & $12.116,70$ & & & $16.207,08$ \\
\hline Pakue Utara & $4.100,79$ & $6.444,17$ & & $18.705,45$ & $29.250,41$ \\
\hline Porehu & $6.860,97$ & $21.782,96$ & $5.381,29$ & $25.076,82$ & $59.102,04$ \\
\hline Ranteangin & 2.154,57 & $7.147,29$ & $1.163,91$ & & $10.465,77$ \\
\hline Watunohu & $2.998,58$ & 203,60 & & & $3.202,18$ \\
\hline Wawo & $2.841,47$ & $22.130,69$ & 228,72 & & $25.200,88$ \\
\hline Total & $60.977,75$ & $163.376,51$ & $20.258,94$ & $65.887,63$ & $310.500,83$ \\
\hline
\end{tabular}

lahan, dan resiko bencana. Informasi tambahan adalah dengan menggunakan data statistik produktifitas secara time series, dan pengukuran lapangan. Kerangka kerja penentuan lahan kritis dan potensi kritis dapat dilihat pada gambar 1.

\section{HASIL DAN PEMBAHASAN}

\section{Analisis Lahan Kritis Kabupaten Kolaka Utara}

Berdasarkan peta status kawasan hutan, lahan di Kolaka Utara di dominasi oleh Hutan lindung dengan luas 163.376,51 ha ( $53 \%$ ), diikuti oleh hutan produksi terbatas $65.887,63$ ha $(21.2$ $\%)$, kawasan budidaya $60.977,75$ ha $(19,6 \%)$ dan hutan produksi konversi $20.258,94$ ha $(6,5 \%)$. Untuk lebih jelasnya dapat dilihat pada tabel 1.

Berdasarkan hasil interpretasi citra ASTER diperoleh bahwa kondisi penutupan dan penggunaan lahan di Kabupaten Kolaka Utara terdiri atas Alang-alang, Bakau, Belukar, Cengkeh, Hutan, Kebun Campuran, Kebun Kakao, Pemukiman, Kelapa, Savana, Sawah, Semak, dan Tambak. Penggunaan dan Penutupan Lahan menyebar pada kawasan hutan dan kawasan budidaya. Penggunaan dan penutupan lahan

Table 2. Conditions of land use and land cover in each forest region in Kolaka Utara Based Image Interpretation

\begin{tabular}{|c|c|c|c|c|c|}
\hline \multirow[b]{2}{*}{$\begin{array}{l}\text { Land use /Land } \\
\text { cover }\end{array}$} & \multicolumn{4}{|c|}{ Wide distribution (Ha) } & \multirow[b]{2}{*}{ Total } \\
\hline & Cultivate Area & $\begin{array}{c}\text { Protection } \\
\text { Forest }\end{array}$ & $\begin{array}{c}\text { Production Foerst } \\
\text { Convertion }\end{array}$ & $\begin{array}{c}\text { Production } \\
\text { Forest Limited }\end{array}$ & \\
\hline Alang-alang & 127,71 & & 4,43 & 42,27 & 174,41 \\
\hline Bakau & 696,76 & 195,76 & & & 892,52 \\
\hline Belukar & $4.911,22$ & $2.493,75$ & $2.805,73$ & $1.404,70$ & $11.615,40$ \\
\hline Cengkeh & $3.682,10$ & 16,45 & 369,38 & & $4.067,93$ \\
\hline Hutan & $1.414,60$ & $115.805,83$ & $4.107,10$ & $56.522,49$ & $177.850,02$ \\
\hline Kebun campuran & $15.189,82$ & 465,41 & $2.070,67$ & 791,86 & $18.517,76$ \\
\hline Kebun Kakao & $30.397,97$ & $43.553,85$ & $10.765,82$ & $6.349,16$ & $91.066,80$ \\
\hline Kelapa & 253,78 & & & & 253,78 \\
\hline Pemukiman & $2.336,22$ & 0,07 & 135,81 & 10,65 & $2.482,75$ \\
\hline Savana & 1,97 & 550,46 & & 470,56 & $1.022,99$ \\
\hline Sawah & $1.290,67$ & & & 2,09 & $1.292,76$ \\
\hline Semak & 151,11 & 231,08 & & 293,85 & 676,04 \\
\hline Tambak & 523,82 & 63,85 & & & 587,67 \\
\hline Total & $60.977,75$ & $163.376,51$ & $20.25,94$ & $65,887.63$ & $310.500,83$ \\
\hline
\end{tabular}


Table 3. Distribution critical land and critical potential based on Forest area and cultivate area in Kolaka Utara Regency

\begin{tabular}{lrrrrr}
\hline \multirow{2}{*}{ Land criticals Wide distribution (ha) } & \multirow{2}{*}{ Total } \\
\cline { 2 - 5 } & Cultivate Area & \multicolumn{1}{c}{ Protection } & \multicolumn{1}{c}{$\begin{array}{c}\text { Protection } \\
\text { Forest }\end{array}$} & $\begin{array}{c}\text { Porest } \\
\text { Forest Limited }\end{array}$ & \\
\hline Tidak kritis & $34.538,32$ & $116.001,66$ & $4.238,50$ & $36.124,33$ & $190.902,81$ \\
Potensial kritis & $13.956,42$ & 79,63 & $4.353,24$ & $20.651,67$ & $39.040,96$ \\
Agak kritis & $4.148,27$ & $4.176,87$ & $5.110,57$ & 77,72 & $13.513,43$ \\
Kritis & $1.728,13$ & $31.028,74$ & $6.552,20$ & $8.225,14$ & $47.534,21$ \\
Sangat kritis & $6.606,61$ & $12.089,61$ & 4,43 & 808,77 & $19.509,42$ \\
\hline Total & $60.977,75$ & $163.376,51$ & $20.258,94$ & $65.887,63$ & $310.500,83$ \\
\hline
\end{tabular}

memilki luas terbesar secara berurut adalah hutan seluas $177.850,02$ ha $(57,3 \%)$, kebun kakao seluas $91.066,80$ ha $(29,3 \%)$, kebun campuran seluas $18.517,76$ ha $(6,0 \%)$, belukar seluas $11.615,40$ ha $(3,7 \%)$, dan cengkeh seluas $4.067,93$ ha $(1,3 \%)$. Untuk lebih jelasnya dapat dilihat pada tabel 2.

Lahan kritis dan potensial kritis menyebar pada semua kawasan baik kawasan hutan maupun di luar kawasan hutan. Luas lahan potensial kritis adalah $39.040,96$ ha $(12,6 \%)$, lahan agak kritis seluas $13.513,43$ ha $(4,4 \%)$, lahan kritis seluas 47.534,21 ha, (15,3\%), dan lahan sangat kritis seluas $19.509,42$ ha $(6,3 \%)$, sedangkan sisanya seluas $190.902,81$ ha $(61,5$ $\%$ ) adalah lahan tidak kritis. Penyebaran dan luas lahan kritis dan potensial kritis dapat dilihat pada tabel 3 dan penyebarannya berdasarkan fungsi kawasan dapat dilihat pada gambar 2, 3, dan 4 .

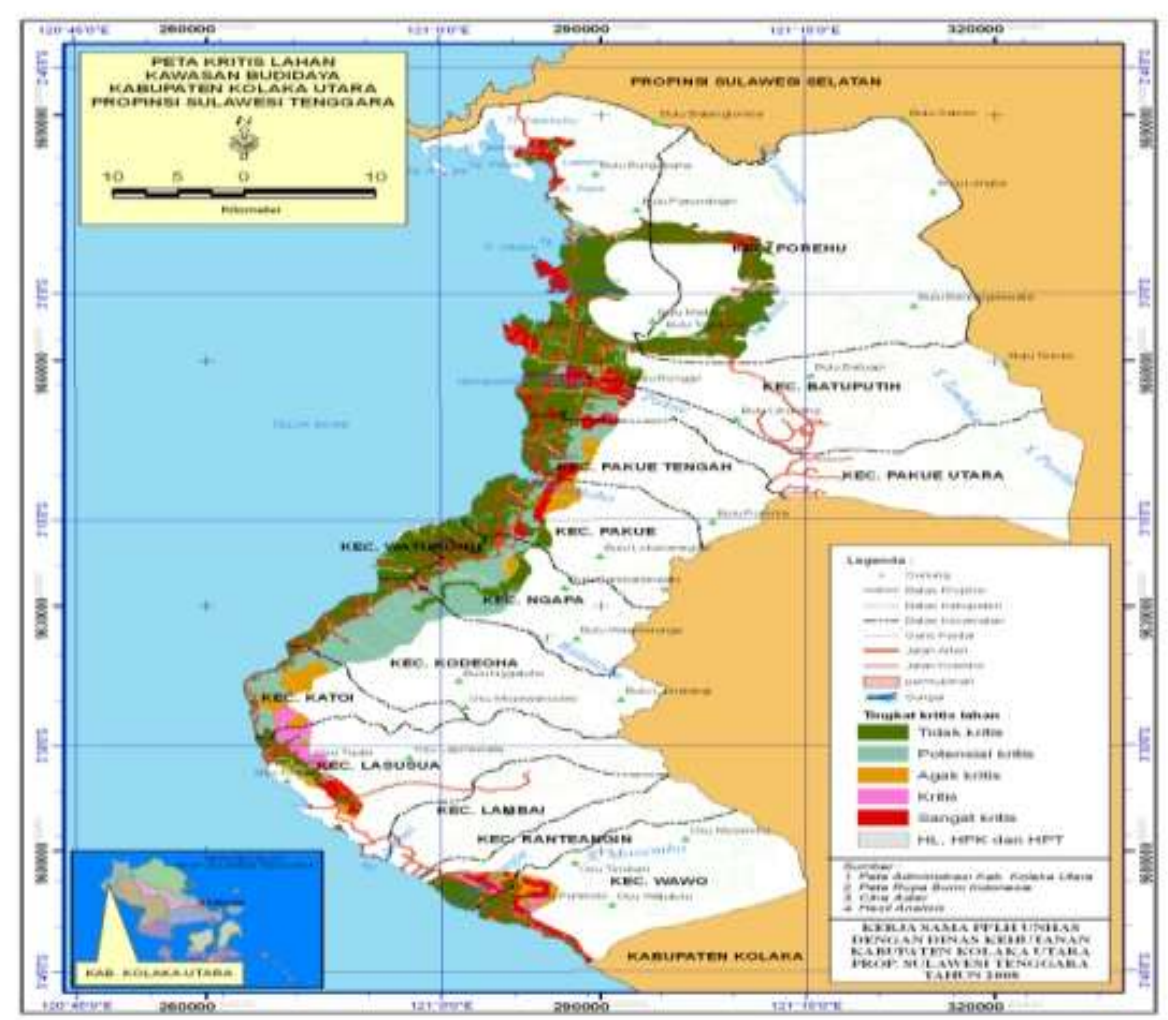

Figure 2. Distribution critical land and critical potential based on Cultivate area in Kolaka Utara Regency 


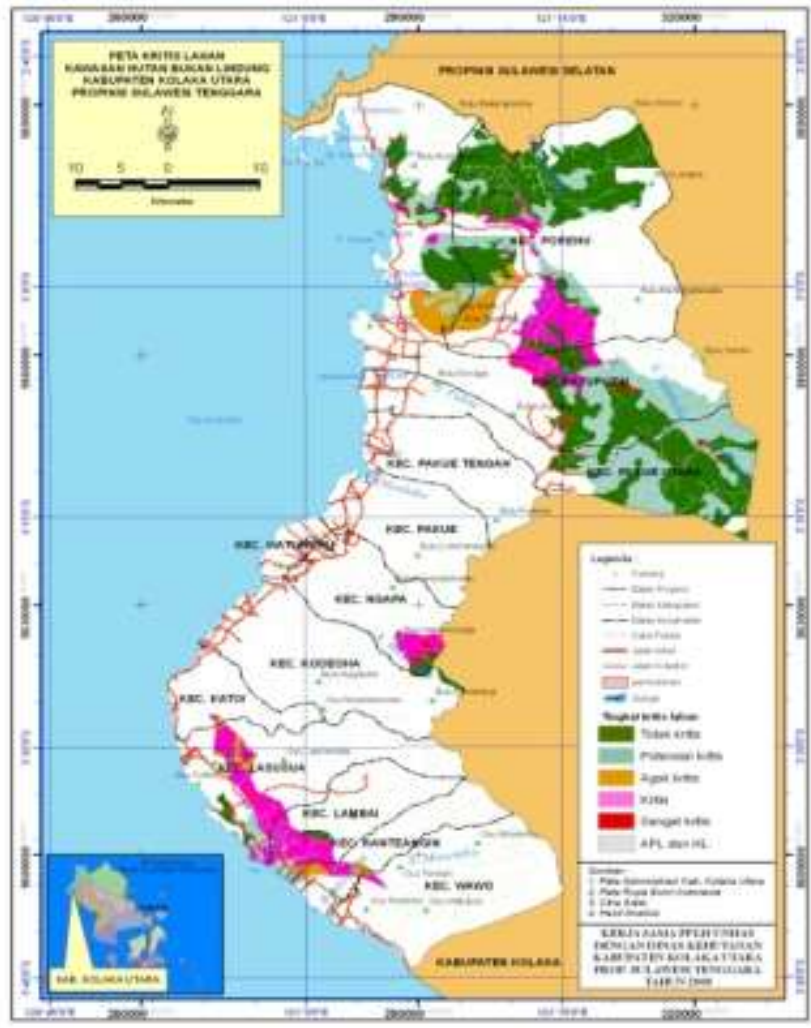

Figure 3. Distribution critical land and critical potential based on non Protection Forest in Kolaka Utara Regency

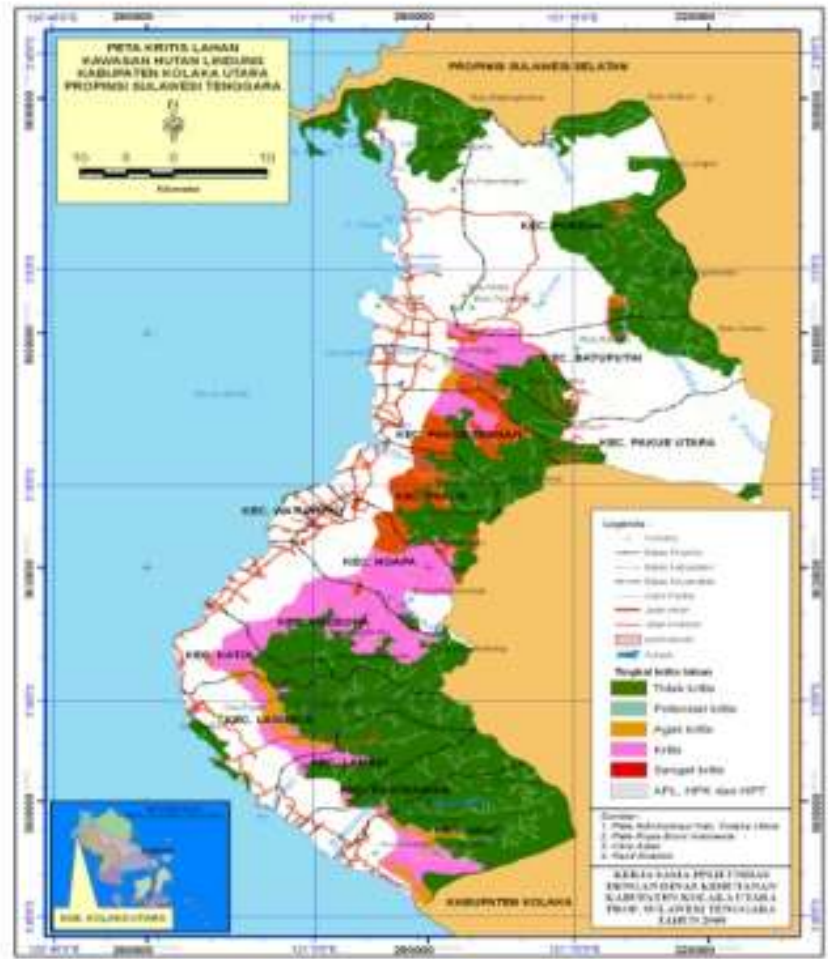

Figure 4. Distribution critical land and critical potential based on Protection Forest in Kolaka Utara Regency 
Luas kawasan hutan di Kolaka Utara sebesar $80,4 \%$ sedangkan luas kawasan budidaya hanya sebesar $19,6 \%$. Tingginya luas kawasan hutan merupakan potensi meningkatnnya lahan kritis dan potensial kritis. Penggunaan lahan berupa kebun kakao, cengkeh, kebun campuran, pemukiman, sawah dan tambak umumnya ditemukan dalam kawasan hutan baik hutan konversi, hutan produksi terbatas, maupun hutan lindung. Dari $91.066,80$ ha kebun kakao, terdapat $60.668,83$ ha di dalam kawasan hutan atau sekitar $66,6 \%$.

Berdasarkan hasil interpretasi citra diperoleh bahwa kebun campuran, kebun kakao, cengkeh dan pemukiman tersebar pada kawasan hutan. Kondisi tersebut menyebabkan lahan menjadi potensial kritis karena tidak sesuai dengan fungsi peruntukannya dengan penggunaan lahan saat ini. Sedangkan yang menyebabkan lahan menjadi agak kritis, kritis, dan sangat kritis adalah ditemukannya penggunaan lahan/penutupan lahan berupa Alang-alang, belukar, semak dalam kawasan hutan.

\section{KESIMPULAN}

Rendahnya produktifitas lahan pada masingmasing lahan yang tidak sesuai dengan peruntukannya menyebabkan lahan menjadi potensial kritis dan lahan kritis. Lahan kritis dan potensial kritis menyebar pada semua kawasan baik di luar kawasan hutan (budidaya) maupun dalam kawasan hutan.

\section{DAFTAR PUSTAKA}

Baja S. 2005. Aplikasi GIS dalam Pengelolaan Wilayah Pesisir Terpadu. Makalah.

Baja S, Chapman DM, Dragovich D. (2002). A conceptual model for defening and assessing land management unit using a fuzzy modeling approach in GIS environment. Environmental Management, $29: 647-661$.

Baja S dan Sallatu A.M. (2005) Analisis Penutup Lahan Daerah Maros, Sulawesi Selatan. Berita Inderaja, 4 (7) : a-b.

Departemen Kehutanan 2004. Petunjuk Teknis Penyusunan Data Spasial Lahan Kritis. Departemen Kehutanan, Direktorat Jendral Rehabilitasi Lahan dan Perhutanan Sosial. Nomor : SK.167N-SET/2004.

King R.B. dan Wardoyo 1999. Land Cover Attributes Should Determine Land Cover Mapping Methodology.

Nugraha S., 2008. Penggunaan Metode Fuzzy Dalam Penentuan Kekritisan Lahan Dengan Menggunakan Sistem Informasi Geografis Di Daerah Subdas Cipeles. Makalah.

Prawira A Y, Wikantika K, dan Hadi F. (2005). Analisis Spasial Lahan Kritis Di Kota Bandung Utara Menggunakan Open Source Grass. Departemen Teknik Geodesi, Fakultas Teknik Sipil dan Lingkungan, Institut Teknologi Bandung - ITB, Jl. Ganesha No. 10, Bandung, Indonesia

Revitalisasi Lahan Kritis Kolaka Utara. (2008). Kerjasama PPLH UNHAS dengan Dinas Kehutanan Kabupaten Kolaka Utara.

Diterima : 12 Desember 2009

\section{Baharuddin}

Lab. Pemanfaatan dan Pengolahan Hasil Hutan Department of Forestry, Forestry Faculty

Hasanuddin University - Indonesia 